\title{
In-hospital and 30-day major adverse cardiac events in patients referred for ST-segment elevation myocardial infarction in Dhaka, Bangladesh
}

\author{
Zubair Akhtar ${ }^{*}$ (D), Mohammad Abdul Aleem ${ }^{1,2}$, Probir Kumar Ghosh', A. K. M. Monwarul Islam³, \\ Fahmida Chowdhury ${ }^{1}$, C. Raina MacIntyre ${ }^{2}$ and Ole Fröbert ${ }^{4}$
}

\begin{abstract}
Background: There is a paucity of data regarding acute phase (in-hospital and 30-day) major adverse cardiac events (MACE) following ST-segment elevation myocardial infarction (STEMI) in Bangladesh. This study aimed to document MACE during the acute phase post-STEMI to provide information.

Methods: We enrolled STEMI patients of the National Institute of Cardiovascular Disease, Dhaka, Bangladesh, from August 2017 to October 2018 and followed up through 30 days post-discharge for MACE, defined as the composite of all-cause death, myocardial infarction, and coronary revascularization. Demographic information, cardiovascular risk factors, and clinical data were registered in a case report form. The Cox proportional hazard model was used for univariate and multivariate analysis to identify potential risk factors for MACE.

Results: A total of 601 patients, mean age $51.6 \pm 10.3$ years, 93\% male, were enrolled. The mean duration of hospital stay was $3.8 \pm 2.4$ days. We found 37 patients (6.2\%) to experience an in-hospital event, and 45 (7.5\%) events occurred within the 30 days post-discharge. In univariate analysis, a significantly increased risk of developing 30-day MACE was observed in patients with more than 12 years of formal education, diabetes mellitus, or a previous diagnosis of heart failure. In a multivariate analysis, the risk of developing 30-day MACE was increased in patients with heart failure (hazard ratio $=4.65 ; 95 \% \mathrm{Cl} 1.64-13.23$ ).
\end{abstract}

Conclusions: A high risk of in-hospital and 30-day MACE in patients with STEMI exists in Bangladesh. Additional resources should be allocated providing guideline-recommended treatment for patients with myocardial infarction in Bangladesh.

Keywords: STEMI, MACE, Low-income setting, Urban setting

*Correspondence: zakhtar@icddrb.org

${ }^{1}$ Programme for Emerging Infections, International Center for Diarrhoeal Diseases, Bangladesh (icddr,b), 68 Shaheed Tajuddin Ahmed Sarani, Mohakhali, Dhaka 1212, Bangladesh

Full list of author information is available at the end of the article

\section{Background}

Acute coronary syndrome is among the leading causes of morbidity and mortality globally [1], but, while the incidence and mortality rates are declining in most developed nations, they are on the rise in developing countries $[2,3]$. The decline may be attributed to increased adherence to treatment guidelines and changes in lifestyle and behavior [4-7]. ST-segment elevation myocardial infarction (STEMI) is the most common acute manifestation

(c) The Author(s) 2021. Open Access This article is licensed under a Creative Commons Attribution 4.0 International License, which permits use, sharing, adaptation, distribution and reproduction in any medium or format, as long as you give appropriate credit to the original author(s) and the source, provide a link to the Creative Commons licence, and indicate if changes were made. The images or other third party material in this article are included in the article's Creative Commons licence, unless indicated otherwise in a credit line to the material. If material is not included in the article's Creative Commons licence and your intended use is not permitted by statutory regulation or exceeds the permitted use, you will need to obtain permission directly from the copyright holder. To view a copy of this licence, visit http://creativecommons.org/licenses/by/4.0/. The Creative Commons Public Domain Dedication waiver (http://creativeco mmons.org/publicdomain/zero/1.0/) applies to the data made available in this article, unless otherwise stated in a credit line to the data. 
of coronary artery disease [8], accounting for approximately one-third of acute coronary syndromes in both developed and developing countries $[9,10]$. In economically disadvantaged areas like Bangladesh, the prevalence of coronary artery disease and STEMI remains mostly unknown, and only small scale epidemiological surveys provide evidence of its increase [11].

Myocardial infarction is two to three times more common in patients who have survived an earlier STEMI than in the general population [12]. Older age, no revascularization procedure, and comorbidities have been identified as significant risk factors for recurrence [12]. Most studies of post-STEMI outcomes focus on the acute phase, inhospital and 30 days post-discharge, after the index event $[13,14]$. A literature search produced only a single study from Bangladesh describing post-STEMI outcomes as a composite of major adverse cardiac events (MACE) in a rural setting [15].

In a resource-limited setting, it is not always feasible to adopt the best treatment strategies for the management of STEMI. Differences in epidemiological, as well as clinical factors, may contribute to greater risk of adverse events following STEMI $[16,17]$ that can potentially impact patient-specific outcomes [18]. This situation exists even in the large tertiary care cardiac hospital in the capital city of Dhaka, as STEMI patients referred from throughout Bangladesh receive treatment here. Bangladesh, with rapidly progressing urbanization, is undergoing a demographic and epidemiological transition from infectious diseases to non-communicable diseases as primary areas of concern $[19,20]$. Common behavioural, metabolic, and physiological risk factors of coronary artery disease are prevalent in the Bangladesh population [21, 22]. In light of this transition, and considering the paucity of in-hospital and 30-day MACE data in urban locations in Bangladesh, we aimed to determine MACE rates in the acute phase post-STEMI for evidencebased guidance to inform the mobilization of resources for therapeutic strategies in STEMI.

\section{Methods}

We conducted a prospective longitudinal observational study at the National Institute of Cardiovascular Diseases (NICVD), Dhaka, from August 2017 through October 2018. The NICVD is the largest public tertiary care cardiac hospital in Bangladesh, managing patients with cardiovascular disorders from throughout the country. Study-appointed physicians reviewed NICVD hospital admission records and visited patients admitted to the cardiology wards to identify potential subjects aged $\geq 18$ years hospitalized with a STEMI. STEMI diagnosis was confirmed based on ST-segment elevation in the electrocardiogram in the hospital records. Informed written consent to participate in the study was obtained for collection of extensive baseline and outcome information. The study was approved by the icddr,b institutional review board prior to enrolling participants.

\section{Data collection}

Enrolled patients were followed up during hospitalization and for 30 days post-discharge. Study physicians recorded sociodemographic data, cardiovascular risk factors, and clinical data on a case report form. They also extracted data related to medical history from the medical records of the patient records file and verified through clinical examination. A respondent was considered hypertensive when the average of two or more diastolic blood pressure (BP) measurements on at least two subsequent visits was $\geq 90 \mathrm{~mm} \mathrm{Hg}$ or when the average of multiple systolic BP readings on two or more subsequent visits was consistently $\geq 140 \mathrm{~mm} \mathrm{Hg}$ in the hospital records [23]. A patient was confirmed to be diabetic based on either of the laboratory findings of plasma glucose: $\mathrm{HbA1c} \geq 48 \mathrm{mmol} / \mathrm{mol}$; random plasma glucose $\geq 11.1 \mathrm{mmol} / \mathrm{l}$; fasting plasma glucose $\geq 7.0 \mathrm{mmol} / \mathrm{l}$ or oral glucose tolerance test 2 -h glucose in venous plasma glucose $\geq 11.1 \mathrm{mmol} / \mathrm{l}$ [24]. A respondent was diagnosed with dyslipidemia according to American heart association's classification corresponding to the a total cholesterol $>5.2 \mathrm{mmol} / \mathrm{l}(200 \mathrm{mg} / \mathrm{dl})$ or low-density lipoprotein $(\mathrm{LDL})>3.4 \mathrm{mmol} / \mathrm{l}(130 \mathrm{mg} / \mathrm{dl})$, high-density lipoprotein $(\mathrm{HDL})<0.9 \mathrm{mmol} / \mathrm{l}(35 \mathrm{mg} / \mathrm{dl})$, or triglycerides $>1.7 \mathrm{mmol} / \mathrm{l}(150 \mathrm{mg} / \mathrm{dl})$ or a combination thereof [25]. Body mass index (BMI) was calculated by body weight measured in kilograms divided by height in meters squared [26]. On day 31, following discharge from hospital, study physicians made calls to subjects/ family members to record any MACE during the past 30 days. A MACE was defined as all-cause death, nonfatal myocardial infarction, or a revascularization procedure including Percutaneous coronary intervention (PCI) or Cronary artery bypass grafting (CABG) [27]. Similar to a previously published study, if more than one MACE occurred during the follow-up period, the most severe endpoint (all-cause death $>$ myocardial infarction $>$ revascularization) was selected for the 30-day MACE analysis [28]. Unplanned revascularizations were only considered for MACE.

\section{Data analysis}

Sociodemographic information and cardiovascular risk factors such as underlying chronic conditions, smoking, family history of cardiovascular disease, previous coronary revascularization procedures, and heart failure were summarized using descriptive statistics. Data of access to water, sanitation, hygiene, and characteristics of 
housing were collected to classify the wealth index [29] using a principal component analysis [30]. Clinical data including symptoms, cardiac troponin I (cTn-I) level at admission, and location of STEMI based on electrocardiogram/echocardiogram findings were summarized using descriptive statistics.

Pearson's $\chi^{2}$ tests were used to analyse categorical variables, and non-parametric Wilcoxon rank-sum tests were conducted for continuous variables in patients with or without events in the 30-day follow-up period. The event rates and 95\% confidence intervals (CI) were tabulated for the in-hospital and post-discharge 30-day follow-up periods.

Univariate and multivariate Cox regression models were used to estimate risk factors for events. Hazard ratios (HR) and the corresponding 95\% CI adjusted for covariates were calculated. Based on literature review and clinical input, 12 risk factors were included in analysis: age, sex, wealth index, education level, location of residence (urban/rural), hypertension, diabetes mellitus (DM), dyslipidemia, previous myocardial infarction, tobacco use, family history of cardiovascular disease, and obesity. Covariates that were significant in the univariate analyses at the $p \leq 0.20$ level were included in the multivariable model. A goodness-of-fit test of the multivariable model was conducted, and the $p$ values from Wald tests of the individual variables were used to identify variables that could be excluded from the model to remove any residual effect. Based on the goodness-of-fit test, seven variables were included in the final Cox regression model. The HR for univariate and multivariate models, together with the respective $95 \% \mathrm{CI}$, are reported. Among the seven variables in the multivariate analysis, corresponding adjusted HRs were not reported for confounding variables of age and education. A $p$ value $\leq 0.05$ was considered significant. All analyses were performed using Stata v. 13 (StataCorp LP, College Station, TX, USA).

\section{Results}

From August 2017 through October 2018, 601 patients, mean age $51.6[S D \pm 10.3]$ years, range $24-80,93 \%$ (559) male, were diagnosed with STEMI based on clinical presentation at admission and electrocardiogram (ECG) findings and included in the study. No patient was lost to follow-up. Baseline data are presented in Table 1. Twothirds $(389 / 601)$ of patients had a family history of cardiovascular disease and 25\% (148/601) had diabetes mellitus. Post-MI discharge, 95\% (573/601) of patients were prescribed antiplatelet agents like acetylsalicylic acid (ASA) and P2Y12 inhibitors, 90\% (540/601) were prescribed statins, 62\% (371/601) were prescribed nitrates, 51\% $(305 / 601)$ were prescribed angiotensin-converting
Table 1 Baseline characteristics of 601 STEMI patients in Dhaka, Bangladesh (August 2017-October 2018)

\begin{tabular}{|c|c|}
\hline Characteristics & Number (\%) \\
\hline \multicolumn{2}{|l|}{ Age (years) } \\
\hline Mean age (SD) & $51.6( \pm 10.3)$ \\
\hline$<40$ & $75(12.5)$ \\
\hline $40-64$ & $450(74.9)$ \\
\hline$\geq 65$ & $76(12.7)$ \\
\hline \multicolumn{2}{|l|}{ Sex } \\
\hline Male & $559(93.0)$ \\
\hline \multicolumn{2}{|l|}{ Location of residence } \\
\hline Rural & $275(45.8)$ \\
\hline Urban & $326(54.2)$ \\
\hline \multicolumn{2}{|l|}{ Education, years of school attendance } \\
\hline None & $154(25.6)$ \\
\hline $1-5$ & $249(41.4)$ \\
\hline $6-10$ & $60(10.0)$ \\
\hline $11-12$ & $57(9.5)$ \\
\hline$\geq 13$ & $81(13.5)$ \\
\hline \multicolumn{2}{|l|}{ Wealth Index [29] } \\
\hline Poorest & $139(23.1)$ \\
\hline Poorer & $107(17.8)$ \\
\hline Middle & $122(20.3)$ \\
\hline Wealthier & $163(27.1)$ \\
\hline Wealthiest & $70(11.7)$ \\
\hline \multicolumn{2}{|l|}{ Medical history } \\
\hline Hypertension & $230(38.3)$ \\
\hline Diabetes mellitus & $148(24.6)$ \\
\hline Dyslipidemia & $60(10.0)$ \\
\hline Family history of CVD & $389(64.7)$ \\
\hline Body Mass Index $>25$ & $212(37.3)$ \\
\hline Currently smoking & $410(68.2)$ \\
\hline Smokeless tobacco use & $56(12.2)$ \\
\hline Alcohol consumption & $12(2.0)$ \\
\hline Previous Ml & $54(9.0)$ \\
\hline Previous heart failure & $11(1.8)$ \\
\hline Previous revascularization & $8(1.3)$ \\
\hline \multicolumn{2}{|l|}{ Discharge medications } \\
\hline $\mathrm{ASA}+\mathrm{P} 2 \mathrm{Y} 12$ inhibitor combination & $573(95.3)$ \\
\hline Statins & $540(89.9)$ \\
\hline Nitrates & $371(61.7)$ \\
\hline ACE inhibitors & $305(50.7)$ \\
\hline$\beta$-blockers & $266(44.3)$ \\
\hline Anti-diabetic agents & $75(12.5)$ \\
\hline
\end{tabular}

ACE inhibitor Angiotensin converting enzyme inhibitor, ASA acetylsalicylic acid, $C V D$ cardiovascular disease, $M I$ myocardial infarction, $S D$ standard deviation

enzyme (ACE) inhibitors and 44\% (266/601) were prescribed $\beta$-blockers (Table 1).

Presenting symptoms at hospital are listed in Table 2. An ECG was conducted in all cases. Cardiac troponin 
Table 2 Characteristics of STEMI patients at presentation in Dhaka, Bangladesh (August 2017-October 2018)

\begin{tabular}{|c|c|c|c|}
\hline Characteristics & MACE $n=80$ & $\begin{array}{l}\text { Without } \\
\text { MACE } \\
n=521\end{array}$ & $p$ value \\
\hline \multicolumn{4}{|l|}{ Symptoms n (\%) } \\
\hline Chest discomfort & 78 (97.5) & $505(96.9)$ & 0.780 \\
\hline Dyspnea & $41(51.3)$ & $181(34.7)$ & 0.004 \\
\hline Sweating & $63(78.8)$ & $413(79.3)$ & 0.915 \\
\hline Nausea & $43(53.8)$ & $245(47.0)$ & 0.262 \\
\hline Vomiting & $31(38.8)$ & $197(37.8)$ & 0.872 \\
\hline Fainting & $6(7.5)$ & $29(5.6)$ & 0.492 \\
\hline \multicolumn{4}{|l|}{ Troponin I level at admission ${ }^{a}$} \\
\hline Mean Troponin I, ng/ml (SD) & $37.3(43.4)$ & $19.4(33.7)$ & 0.002 \\
\hline Not elevated, n (\%) & $2(2.5)$ & $30(5.8)$ & Ref \\
\hline Elevated, n (\%) & $27(33.8)$ & $138(26.6)$ & 0.157 \\
\hline Not available, n (\%) & $51(63.8)$ & $353(67.8)$ & - \\
\hline \multicolumn{4}{|l|}{ Location of STEMI n (\%) } \\
\hline Anterior & $25(31.3)$ & $140(26.9)$ & Ref \\
\hline Anteroseptal & $10(12.5)$ & $79(15.2)$ & 0.383 \\
\hline Inferior & $36(45.0)$ & $247(47.4)$ & 0.467 \\
\hline Lateral & $2(2.5)$ & $9(1.7)$ & 0.775 \\
\hline Other & $7(8.8)$ & $46(8.8)$ & 0.718 \\
\hline
\end{tabular}

Theh bold font was used to indicate that the value is statistically significant, i.e. $p<0.005$

a $\mathrm{n}=197$ subjects had Troponin I level assessed

I (cTn-I) was not available for 67\% (404/601) of cases; however, among those in which it was assessed, $84 \%$ $(165 / 197)$ showed values above the 99th percentile of the upper reference limit. Significantly higher mean values of cTn-I were observed in patients who developed MACE during the 30-day follow-up period compared to patients who did not experience MACE (37.3 ng/ $\mathrm{ml}[ \pm \mathrm{SD} 43.4]$ vs. $19.4 \mathrm{ng} / \mathrm{ml}$ [ \pm SD 33.7], $p=0.002)$. Based on ECG/echocardiogram, the most common location of infarct was in the inferior $(47 \%, 283 / 601)$ followed by the anterior $(27 \%, 165 / 601)$ heart wall.

The mean duration of hospital stay was $3.8( \pm \mathrm{SD}$, 2.4) days. Hospitalization of patients who experienced in-hospital MACE was significantly longer than recorded for those who experienced post-discharge 30-day MACE (5.6 days, $[ \pm$ SD 4.5] vs. 3.7 days, $[ \pm$ SD $2.1] ; p=0.022)$. Thirty-seven $(6.2 \% ; 95 \%$ CI $4.2-8.1)$ in-hospital events included 19 (3.2\%) all-cause deaths and $18(3.0 \%)$ unplanned revascularization procedures. Within 30 days post-discharge, 45 (7.5\%; 95\% CI 5.49.6) MACE were recorded, including revascularization procedures (PCI or CABG) in $26(4.3 \%)$ patients, 15 all-cause deaths $(2.5 \%)$, and $4(0.7 \%)$ recurrent MIs. Two patients undergoing unplanned revascularization during the hospital stay died during the 30-day followup period. In total, 80 MACE occurred during the inhospital and 30-day follow-up, i.e. 13.3\% (80/601) of all patients experienced a MACE (Table 3$)$.

The univariate analysis revealed significantly increased risk of MACE in patients with greater than 12 years of education, diabetes mellitus, or a previous history of heart failure. We also observed a numerically elevated risk $(\mathrm{HR}=1.79 ; 95 \% \mathrm{CI} 0.95-3.36)$ in patients $\geq 65$ years, but this did not reach statistical significance. In multivariate analysis, after adjusting for age and education, heart failure $(\mathrm{HR}=5.23$; 95\% CI $1.83-14.92)$ remained a significant risk factor for 30-day MACE (Fig. 1).

\section{Discussion}

Our prospective study from the largest tertiary cardiac hospital in Bangladesh revealed that 13\% of patients admitted with STEMI experienced a MACE within the 30 days post-discharge (Fig. 2). This finding is lower than the 23\% MACE within 30 days post-STEMI found in a study in rural Bangladesh [15].

Our 30-day MACE rate following STEMI is much higher compared to reports from the Netherlands (3\%), India (5\%), and Brazil (10\%) [31-33]. The in-hospital MACE rate was lower in our study population compared with results of recent studies from China (12\%), Canada $(9 \%)$, and India (8\%) $[32,34,35]$. We were, however, unable to compare our results with regional data because of the paucity of data available of in-hospital MACE in Bangladesh.

Revascularization procedures were the most frequent post-discharge MACE in our study. While most

Table 3 In-hospital and 30-day MACE in STEMI patients in Dhaka, Bangladesh (August 2017-October 2018)

\begin{tabular}{llll}
\hline MACE & In hospital $\mathbf{n}(\%)$ & $\mathbf{3 0}$ day $\mathbf{n}(\%)$ & Total \\
\hline Overall & $37(6.2)(95 \%$ Cl 4.2-8.1) & $45(7.5)(95 \%$ Cl 5.4-9.6) & $\begin{array}{c}(95 \% \mathrm{Cl} \\
(13.3)\end{array}$ \\
& & & $10.6-16.0)$ \\
All-cause deaths & $19(3.2)$ & $15(2.5)$ & $34(5.7)$ \\
Revascularization & $18(3.0)$ & $26(4.3)$ & $44(7.3)$ \\
Recurrent Ml & 0 & $4(0.7)$ & $4(0.7)$ \\
\hline
\end{tabular}

\footnotetext{
a Two in-hopital MACE cases experienced more severe MACE post-discharge
} 

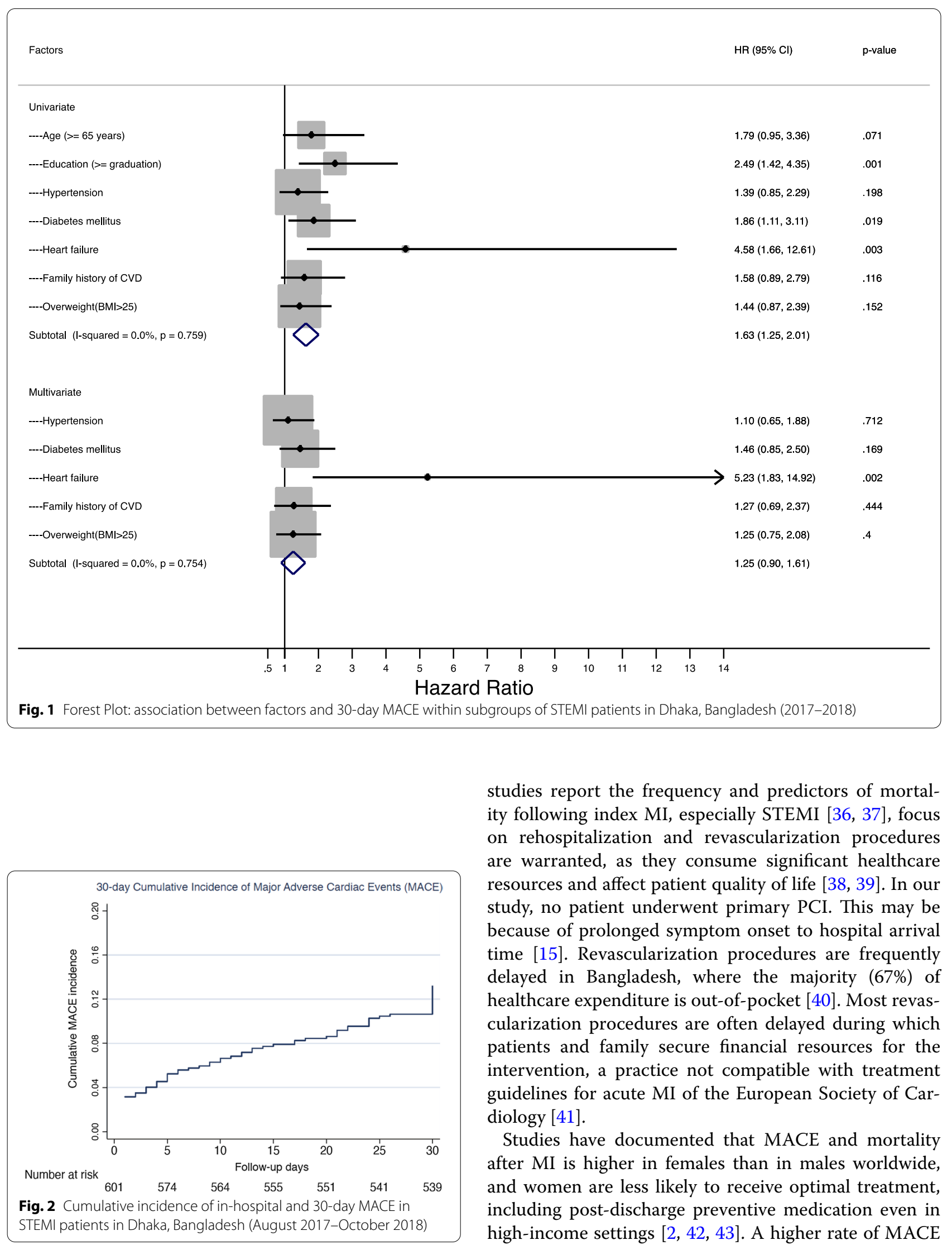

studies report the frequency and predictors of mortality following index MI, especially STEMI [36, 37], focus on rehospitalization and revascularization procedures are warranted, as they consume significant healthcare resources and affect patient quality of life [38, 39]. In our study, no patient underwent primary PCI. This may be because of prolonged symptom onset to hospital arrival time [15]. Revascularization procedures are frequently delayed in Bangladesh, where the majority $(67 \%)$ of healthcare expenditure is out-of-pocket [40]. Most revascularization procedures are often delayed during which patients and family secure financial resources for the intervention, a practice not compatible with treatment guidelines for acute MI of the European Society of Cardiology [41].

Studies have documented that MACE and mortality after MI is higher in females than in males worldwide, and women are less likely to receive optimal treatment, including post-discharge preventive medication even in high-income settings [2, 42, 43]. A higher rate of MACE 
and mortality among women has been attributed to biological sex differences and gender differences influenced by social, environmental, and community factors [44, 45]. In a large registry-based study from 125 centres in India, only $22.6 \%$ of patients with acute coronary syndrome were female [46]. There were few female patients (7\%) in our study. This underrepresentation of females as participants was also a factor in previous studies conducted in Bangladesh and neighboring countries, and represents the known lower risk of cardiovascular disease in women prior to menopause [15, 47-50]. Women tend to show atypical symptoms of acute coronary events and are less likely to present with chest pain [51]. Hence, they are less likely to seek hospital care [52] and optimal treatment [53]. According to the Bangladesh demographic and health survey report of 2014 , only $14.1 \%$ of women have decision-making capacity with respect to their own healthcare, and three in ten women reported that their husband is the main decision maker for their healthcare [54]. Women are underrepresented in cardiology studies and our findings are a stark reminder that female sex should be considered in designing and analyzing future studies [55].

Social and cultural factors may also explain delayed hospitalization or not seeking healthcare. A quarter of our study participants had no formal education, and $41 \%$ had education only at the primary level (Table 1 ). Prevous studies in Bangladesh have documented a low level of education limiting access to healthcare and negatively affecting health care seeking decisions $[56,57]$.

We found an elevated risk of MACE among patients aged $\geq 65$ years that did not reach statistical significance, most likely because of the low numbers of such patients (13\%) in our cohort. Nevertheless, increasing age is considered a significant risk factor for mortality after an acute myocardial infarction [58-60]. The choice of treatment for the elderly should be determined by early clinical assessment, time of presentation after STEMI, and underlying comorbidities [61].

We also found $25 \%$ of our respondents with DM to have a numerically higher risk of MACE, but it did not reach statistical significance. The role of DM in ACS deserves much clinical and therapeutic attention. The inflammatory status and altered glucose homeostasis with DM could cause endothelial dysfunction $[62,63]$ even in the absence of significant coronary artery stenoses [63] such as in the condition of acute myocardial infarction specifically for patients with multi-vessel coronary stenosis [64] and high thrombus burden in STEMI [65]. Furthermore, altered endothelial function may result in restenosis after revascularization by PCI [66] and may sustain a high thrombus burden [67]. Control of inflammatory status could be an appropriate therapeutic option to reduce the burden of cardiovascular disease [62]. Hypoglycemic drugs with anti-inflammatory properties may ameliorate conditions by directly stabilizing coronary plaques [64]. Even after STEMI and guidelinerecommended treatment, glycemic control not only has shown to reduce thrombus burden [68] but also improve myocardial repair [69].

We found a statistically significant higher risk of 30-day MACE among patients who had a history of heart failure before the recent STEMI. Heart failure, together with MI, has been considered a major driver of morbidity and mortality. With an established contribution of heart failure to morbidity and mortality after MI, early risk stratification through clinical and laboratory assessment, together with preventative therapeutic strategies, is required to reduce in-hospital and 30-day MACE [70].

Several limitations warrant attention while interpreting our study findings. First, this was a relatively small observational study in a single specialized cardiac hospital in the capital city of Bangladesh, and study results may not generalize to the entire country. Further studies from multiple centers should be undertaken to ascertain rates of MACE after STEMI in larger cohorts. Secondly, in a number of patients with dyspnea a diagnosis of heart failure was likely missed due to strained resources and this might explain the low number of patients diagnosed with heart failure available for our analyses. Thirdly, data of the 30-day follow-up was obtained through phone calls by study physicians with no documented evidence of patients' adherence to post-discharge therapy and of MACE outcomes to verify responses from patients and or family members. In addition, troponin levels were not available for most partipants. In future studies, review of records of the treatment provided is recommended in determining MACE outcomes. Despite these limitations, this research offers essential information of in-hospital and 30-day MACE after STEMI in Bangladesh.

\section{Conclusions}

The study shows a considerable risk of in-hospital and 30-day MACE occurring in patients referred with STEMI in Bangladesh. Our findings highlight the need for resources to provide guideline-recommended treatment for patients with myocardial infarction.

\footnotetext{
Abbreviations

ASA: Acetylsalicylic acid; ACE inhibitor: Angiotensin converting enzyme inhibitor; BMI: Body mass index; BP: Blood pressure; CABG: Cronary artery bypass grafting; $\mathrm{Cl}$ : Confidence intervals; $\mathrm{CTn}-\mathrm{l}$ : Cardiac troponin I; DM: Diabetes mellitus; ECG: Electrocardiogram; HbA1c: Glycated hemoglobin; HDL: High-density lipoprotein; HR: Hazard ratio; LDL: Low-density lipoprotein; MACE: Major adverse cardiac events; MI: Myocardial infarction; NICVD: National Institute of Cardiovascular Disease; PCI: Percutaneous coronary intervention; STEMI: STsegment elevation myocardial infarction.
} 


\section{Acknowledgements}

The authors are grateful to the study data collection team and study participants for their valuable data. We also acknowledge the support of NICVD authority in conducting this study.

\section{Authors' contributions}

ZA wrote the paper and performed data analysis. MAA and CRM conceived the study and carried out with AI and ZA. PKG developed data distribution and visualization. FC and CRM provided critical feedback. OF provided overall guidance for developing and writing the paper. All authors have read and approved the final manuscript.

\section{Funding}

The Swedish International Development Cooperation Agency funded the study. However, the donor did not have any role in the study design, implementation, analysis, and interpretation of data and in writing this manuscript. icddr,b is grateful to the Governments of Bangladesh, Canada, Sweden, and the UK for providing core/unrestricted support.

\section{Availability of data and materials}

Data generated during the study are subject to a data access policy of icddr,b and are available from icddrb's research administration on reasonable request through the corresponding author.

\section{Ethics approval and consent to participate}

The study was approved by the icddr,b institutional review board prior to enrolling participants, and informed written consent to participate in the study was obtained.

\section{Consent for publication}

Not applicable.

\section{Competing interests}

None of the authors have any financial, personal, or professional relationships to disclose.

\section{Author details}

${ }^{1}$ Programme for Emerging Infections, International Center for Diarrhoeal Diseases, Bangladesh (icddr,b), 68 Shaheed Tajuddin Ahmed Sarani, Mohakhali, Dhaka 1212, Bangladesh. ${ }^{2}$ Faculty of Medicine, University of New South Wales, Sydney, Australia. ${ }^{3}$ Department of Cardiology, National Institute of Cardiovascular Diseases Dhaka (NICVD), Dhaka, Bangladesh. ${ }^{4}$ Department of Cardiology, Faculty of Health, Örebro University, Örebro, Sweden.

Received: 24 September 2020 Accepted: 31 January 2021

Published online: 10 February 2021

\section{References}

1. Moran AE, et al. The global burden of ischemic heart disease in 1990 and 2010: the Global Burden of Disease 2010 study. Circulation. 2014;129(14):1493-501. https://doi.org/10.1161/circulationaha.113.00404 6.

2. Mozaffarian D, et al. Heart disease and stroke statistics-2015 update: a report from the American Heart Association. Circulation. 2015;131(4):e29322. https://doi.org/10.1161/cir.0000000000000152.

3. Nichols M, Townsend N, Scarborough P, Rayner M. Cardiovascular disease in Europe 2014: epidemiological update. Eur Heart J. 2014;35(42):2929. https://doi.org/10.1093/eurheartj/ehu378.

4. Rogers WJ, et al. Trends in presenting characteristics and hospital mortality among patients with ST elevation and non-ST elevation myocardial infarction in the National Registry of Myocardial Infarction from 1990 to 2006. Am Heart J. 2008;156(6):1026-34. https://doi.org/10.1016/j. ahj.2008.07.030.

5. O'Gara PT, et al. 2013 ACCF/AHA guideline for the management of STelevation myocardial infarction: a report of the American College of Cardiology Foundation/American Heart Association Task Force on Practice Guidelines. J Am Coll Cardiol. 2013;61(4):e78-140.

6. Wright RS, et al. 2011 ACCF/AHA Focused update of the guidelines for the management of patients with unstable Angina/Non-ST-elevation myocardial infarction (updating the 2007 guideline): a report of the American College of Cardiology Foundation/American Heart Association Task Force on Practice Guidelines Developed in Collaboration With the American College of Emergency Physicians, Society for Cardiovascular Angiography and Interventions, and Society of Thoracic Surgeons. J Am Coll Cardiol. 2011;57(19):1920-59. https://doi.org/10.1016/j. jacc.2011.02.009.

7. Spring B, et al. Better population health through behavior change in adults: a call to action. Circulation. 2013;128(19):2169-76. https://doi. org/10.1161/01.cir.0000435173.25936.e1.

8. Vogel B, et al. ST-segment elevation myocardial infarction. Nat Rev Dis Primers. 2019;5(1):39. https://doi.org/10.1038/s41572-019-0090-3.

9. Steg PG, et al. Baseline characteristics, management practices, and in-hospital outcomes of patients hospitalized with acute coronary syndromes in the Global Registry of Acute Coronary Events (GRACE). Am J Cardiol. 2002;90(4):358-63. https://doi.org/10.1016/s0002-9149(02)02489 $-x$

10. Dharma S, et al. Organisation of reperfusion therapy for STEMI in a developing country. Open Heart. 2015;2(1):e000240. https://doi.org/10.1136/ openhrt-2015-000240.

11. Islam AKMM, Majumder AAS. Coronary artery disease in Bangladesh: a review. Indian Heart J. 2013;65(4):424-35. https://doi.org/10.1016/j. ihj.2013.06.004

12. Smolina K, Wright FL, Rayner M, Goldacre MJ. Long-term survival and recurrence after acute myocardial infarction in England, 2004 to 2010 Circ Cardiovasc Qual Outcomes. 2012;5(4):532-40.

13. Jernberg $T$, Hasvold $P$, Henriksson M, Hjelm H, Thuresson M, Janzon M Cardiovascular risk in post-myocardial infarction patients: nationwide real world data demonstrate the importance of a long-term perspective. Eur Heart J. 2015;36(19):1 163-70. https://doi.org/10.1093/eurheartj/ehu505.

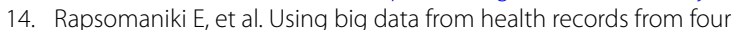
countries to evaluate chronic disease outcomes: a study in 114364 survivors of myocardial infarction. Eur Heart J Qual Care Clin Outcomes. 2016;2(3):172-83. https://doi.org/10.1093/ehjqcco/qcw004.

15. Kim DY, Wala Z, Islam S, Islam R, Ahn M. Clinical characteristics and outcomes of ST-segment elevation myocardial infarction in a low income setting in rural Bangladesh. Int J Cardiol Heart Vasc. 2019;23:100376. https ://doi.org/10.1016/j.ijcha.2019.100376.

16. Haffner SM, Lehto S, Rönnemaa T, Pyörälä K, Laakso M. Mortality from coronary heart disease in subjects with type 2 diabetes and in nondiabetic subjects with and without prior myocardial infarction. N Engl J Med. 1998:339(4):229-34

17. Donahoe SM, et al. Diabetes and mortality following acute coronary syndromes. JAMA. 2007;298(7):765-75.

18. Arnold SV, et al. Predicting adverse outcomes after myocardial infarction among patients with diabetes mellitus. Circ Cardiovasc Qual Outcomes. 2016:9(4):372-9.

19. Ahsan Karar Z, Alam N, Kim Streatfield P. Epidemiological transition in rural Bangladesh, 1986-2006. Glob Health Action. 2009;2:1904. https:// doi.org/10.3402/gha.v2i0.1904.

20. Abubakar II, Tillmann T, Banerjee A. Global, regional, and national age-sex specific all-cause and cause-specific mortality for 240 causes of death, 1990-2013: a systematic analysis for the Global Burden of Disease Study 2013. Lancet. 2015;385(9963):117-71. https://doi.org/10.1016/s0140 $-6736(14) 61682-2$.

21. Alam DS, Chowdhury MA, Siddiquee AT, Ahmed S, Niessen LW. Awareness and control of hypertension in Bangladesh: follow-up of a hypertensive cohort. BMJ Open. 2014;4(12):e004983. https://doi.org/10.1136/ bmjopen-2014-004983.

22. World Health Organization. Noncommunicable diseases country profiles 2018; 2018

23. Carretero OA, Oparil S. Essential hypertension: part I: definition and etiology. Circulation. 2000;101(3):329-35.

24. Kerner W, Brückel J. Definition, classification and diagnosis of diabetes mellitus. Exp Clin Endocrinol Diabetes. 2014;122(07):384-6.

25. Kavey RE, Daniels SR, Lauer RM, Atkins DL, Hayman LL, Taubert K. American Heart Association guidelines for primary prevention of atherosclerotic cardiovascular disease beginning in childhood. Circulation. 2003;107(11):1562-6. https://doi.org/10.1161/01.cir.0000061521.15730 .6e. 
26. Quetelet LAJ. Sur l'homme et le développement de ses facultés, ou Essai de physique sociale; 1869.

27. Choi BG, Rha SW, Yoon SG, Choi CU, Lee MW, Kim SW. Association of major adverse cardiac events up to 5 years in patients with chest pain without significant coronary artery disease in the Korean population. J Am Heart Assoc. 2019;8(12):e010541. https://doi.org/10.1161/ jaha.118.010541.

28. Reinstadler SJ, et al. Prognostic value of left ventricular global function index in patients after ST-segment elevation myocardial infarction. Eur Heart J Cardiovasc Imaging. 2015;17(2):169-76. https://doi.org/10.1093/ ehjci/jev129.

29. Rutstein SO, Johnson K. DHS comparative reports 6: the DHS wealth index. Calverton: ORC Macro; 2004.

30. Vyas S, Kumaranayake L. Constructing socio-economic status indices: how to use principal components analysis. Health Policy Plan. 2006;21(6):459-68.

31. Vos NS, et al. Prehospital prasugrel versus ticagrelor in real-world patients with ST-elevation myocardial infarction referred for primary $\mathrm{PCl}$ : procedural and 30-day outcomes. J Invasive Cardiol. 2018;30(12):431-6.

32. Umapathy S, Yadav R, Goswami KC, Karthikeyan G, Parakh N, BahI VK. Prognostic significance of fragmented QRS in patients with ST-elevation myocardial infarction undergoing revascularization. Indian Heart J. 2018;70(Suppl 3):S126-s132. https://doi.org/10.1016/j.ihj.2018.07.014.

33. Berwanger $\mathrm{O}$, et al. Effect of loading dose of atorvastatin prior to planned percutaneous coronary intervention on major adverse cardiovascular events in acute coronary syndrome: The SECURE-PCI Randomized Clinical Trial. JAMA. 2018;319(13):1331-40. https://doi.org/10.1001/ jama.2018.2444.

34. Liu R, et al. Association of thrombocytopenia with in-hospital outcome in patients with acute ST-segment elevated myocardial infarction. Platelets. 2019;30(7):844-53. https://doi.org/10.1080/09537104.2018.1529298.

35. Saw J, et al. Canadian spontaneous coronary artery dissection cohort study: in-hospital and 30-day outcomes. Eur Heart J. 2019;40(15):1188-97. https://doi.org/10.1093/eurheartj/ehz007.

36. Eagle KA, et al. A validated prediction model for all forms of acute coronary syndrome: estimating the risk of 6-month postdischarge death in an international registry. JAMA. 2004;291(22):2727-33. https://doi. org/10.1001/jama.291.22.2727.

37. Boersma $E$, et al. Predictors of outcome in patients with acute coronary syndromes without persistent ST-segment elevation. Results from an international trial of 9461 patients. The PURSUIT Investigators. Circulation. 2000;101(22):2557-67. https://doi.org/10.1161/01.cir.101.22.2557.

38. Arnold SV, Masoudi FA, Rumsfeld JS, Li Y, Jones PG, Spertus JA. Derivation and validation of a risk standardization model for benchmarking hospital performance for health-related quality of life outcomes after acute myocardial infarction. Circulation. 2014;129(3):313-20. https://doi. org/10.1161/circulationaha.113.001773.

39. Arnold SV, et al. Economic impact of angina after an acute coronary syndrome: insights from the MERLIN-TIMI 36 trial. Circ Cardiovasc Qual Outcomes. 2009;2(4):344-53. https://doi.org/10.1161/circoutcom es.108.829523.

40. Mustafa A, Rahman A,Hossain N, Begum T. Bangladesh National Health Accounts 1997-2015 (BNHA-V); 2018.

41. Ibanez B, et al. 2017 ESC Guidelines for the management of acute myocardial infarction in patients presenting with ST-segment elevation: the Task Force for the management of acute myocardial infarction in patients presenting with ST-segment elevation of the European Society of Cardiology (ESC). Eur Heart J. 2018;39(2):119-77.

42. Mozaffarian D, Benjamin EJ, Go AS, Arnett DK, Blaha MJ, Cushman M, de Ferranti S, Després JP, Fullerton HJ, Howard VJ, Huffman MD, Judd SE, Kissela BM, Lackland DT, Lichtman JH, Lisabeth LD, Liu S, Mackey RH, Matchar DB, McGuire DK, Mohler ER 3rd, Moy CS, Muntner P, Mussolino ME, Nasir K, Neumar RW, Nichol G, Palaniappan L, Pandey DK, Reeves MJ, Rodriguez CJ, Sorlie PD, Stein J, Towfighi A, Turan TN, Virani SS, Willey JZ, Woo D, Yeh RW, Turner MB. American heart association statistics committee and stroke statistics subcommittee. Heart disease and stroke statistics - 2015 update: a report from the American heart association. Circulation. 2015;131(4):e29-322. https://doi.org/10.1161/CIR.0000000000 000152.

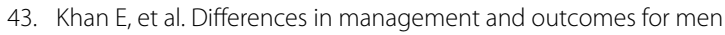
and women with ST-elevation myocardial infarction. Med J Aust. 2018:209(3):118-23.

44. Institute of Medicine Committee on Understanding the Biology of S, Gender D. The National Academies Collection: reports funded by National Institutes of Health. In: Wizemann TM, Pardue ML, editors. Exploring the biological contributions to human health: does sex matter. Washington: National Academies Press; 2001.

45. Institute of Medicine Committee on Women's Health R. Women's health research: progress, pitfalls, and promise. Washington: National Academies Press; 2010.

46. Mohanan PP, et al. Presentation, management, and outcomes of 25 748 acute coronary syndrome admissions in Kerala, India: results from the Kerala ACS Registry. Eur Heart J. 2013;34(2):121-9. https://doi. org/10.1093/eurheartj/ehs219.

47. Karim MA, et al. Risk factors and in-hospital outcome of acute ST segment elevation myocardial infarction in young Bangladeshi adults. BMC Cardiovasc Disord. 2015;15:73. https://doi.org/10.1186/s12872-015-0069-2.

48. Roy SS, Abu Azam STM, Khalequzzaman M, Ullah M, Arifur Rahman M. GRACE and TIMI risk scores in predicting the angiographic severity of non-ST elevation acute coronary syndrome. Indian Heart J. 2018;70(Suppl 3):S250-s253. https://doi.org/10.1016/j.ihj.2018.01.026.

49. Shreshta NR, et al. Presentation and outcome of patients with acute coronary syndromes in eastern Nepal. Swiss Med Wkly. 2011;141:w13174. https://doi.org/10.4414/smw.2011.13174.

50. Prabhakaran D, Jeemon P, Roy A. Cardiovascular diseases in India: current epidemiology and future directions. Circulation. 2016;133(16):1605-20. https://doi.org/10.1161/circulationaha.114.008729.

51. Graham G. Acute coronary syndromes in women: recent treatment trends and outcomes. Clin Med Insights Cardiol. 2016;10:1-10. https:// doi.org/10.4137/cmc.S37145.

52. Singh JA, Lu X, Ibrahim S, Cram P. Trends in and disparities for acute myocardial infarction: an analysis of Medicare claims data from 1992 to 2010. BMC Med. 2014;12:190. https://doi.org/10.1186/s12916-014-0190-6.

53. Nguyen HL, Saczynski JS, Gore JM, Goldberg RJ. Age and sex differences in duration of prehospital delay in patients with acute myocardial infarction: a systematic review. Circ Cardiovasc Qual Outcomes. 2010;3(1):8292. https://doi.org/10.1161/circoutcomes.109.884361.

54. Research NIoP, Training - NIPORT/Bangladesh, Mitra, Associates, ICF International. Bangladesh Demographic and Health Survey 2014. Dhaka, Bangladesh: NIPORT, Mitra and Associates, and ICF International; 2016. https://dhsprogram.com/publications/publication-fr311-dhs-final-repor ts.cfm.

55. Mikhail GW. Coronary heart disease in women. BMJ. 2005:331(7515):4678. https://doi.org/10.1136/bmj.331.7515.467.

56. Parr JD, Lindeboom W, Khanam MA, Pérez Koehlmoos TL. Diagnosis of chronic conditions with modifiable lifestyle risk factors in selected urban and rural areas of Bangladesh and sociodemographic variability therein. BMC Health Serv Res. 2011;11(1):309. https://doi. org/10.1186/1472-6963-11-309.

57. Rasul FB, et al. Determinants of health seeking behavior for chronic noncommunicable diseases and related out-of-pocket expenditure: results from a cross-sectional survey in northern Bangladesh. J Health Popul Nutr. 2019;38(1):48. https://doi.org/10.1186/s41043-019-0195-z.

58. Isaksson RM, Jansson JH, Lundblad D, Näslund U, Zingmark K, Eliasson M. Better long-term survival in young and middle-aged women than in men after a first myocardial infarction between 1985 and 2006. An analysis of 8630 patients in the northern Sweden MONICA study. BMC Cardiovasc Disord. 2011;11:1. https://doi.org/10.1186/1471-2261-11-1.

59. Rapsomaniki $E$, et al. Prognostic models for stable coronary artery disease based on electronic health record cohort of 102023 patients. Eur Heart J. 2014;35(13):844-52. https://doi.org/10.1093/eurheartj/eht533.

60. Nakazato R, et al. Age-related risk of major adverse cardiac event risk and coronary artery disease extent and severity by coronary CT angiography: results from 15187 patients from the International Multisite CONFIRM Study. Eur Heart J Cardiovasc Imaging. 2014;15(5):586-94. https://doi. org/10.1093/ehjci/jet132.

61. Carro A, Kaski JC. Myocardial infarction in the elderly. Aging Dis. 2011;2(2):116-37

62. Sardu C, Paolisso G, Marfella R. Inflammatory related cardiovascular diseases: from molecular mechanisms to therapeutic targets. Curr Pharm 
Des. 2020;26(22):2565-73. https://doi.org/10.2174/138161282666620 0213123029 .

63. Sardu C, et al. Effects of metformin therapy on coronary endothelial dysfunction in patients with prediabetes with stable angina and nonobstructive coronary artery stenosis: the CODYCE multicenter prospective study. Diabetes Care. 2019;42(10):1946-55. https://doi.org/10.2337/dc18-2356.

64. Marfella $\mathrm{R}$, et al. Effects of incretin treatment on cardiovascular outcomes in diabetic STEMI-patients with culprit obstructive and multivessel non obstructive-coronary-stenosis. Diabetol Metab Syndr. 2018;10:1-1. https ://doi.org/10.1186/s13098-017-0304-3.

65. Sardu C, D'Onofrio N, Mauro C, Balestrieri ML, Marfella R. Thrombus aspiration in hyperglycemic patients with high inflammation levels in coronary thrombus. J Am Coll Cardiol. 2019;73(4):530-1. https://doi.org/10.1016/j. jacc.2018.10.074.

66. Sasso FC, et al. Adiponectin and insulin resistance are related to restenosis and overall new PCl in subjects with normal glucose tolerance: the prospective AIRE Study. Cardiovasc Diabetol. 2019;18(1):24. https://doi. org/10.1186/s12933-019-0826-0.

67. Sardu C, et al. Thrombus aspiration in hyperglycemic ST-elevation myocardial infarction (STEMI) patients: clinical outcomes at 1-year follow-up.
Cardiovasc Diabetol. 2018;17(1):152-152. https://doi.org/10.1186/s1293 3-018-0795-8.

68. D'Onofrio N, et al. MicroRNA-33 and SIRT1 influence the coronary thrombus burden in hyperglycemic STEMI patients. J Cell Physiol. 2020;235(2):1438-52. https://doi.org/10.1002/jcp.29064.

69. Marfella R, et al. Peri-procedural tight glycemic control during early percutaneous coronary intervention up-regulates endothelial progenitor cell level and differentiation during acute ST-elevation myocardial infarction: effects on myocardial salvage. Int J Cardiol. 2013;168(4):3954-62. https:// doi.org/10.1016/j.jijcard.2013.06.053.

70. Cahill TJ, Kharbanda RK. Heart failure after myocardial infarction in the era of primary percutaneous coronary intervention: Mechanisms, incidence and identification of patients at risk. World J Cardiol. 2017;9(5):407-15. https://doi.org/10.4330/wjc.v9.i5.407.

\section{Publisher's Note}

Springer Nature remains neutral with regard to jurisdictional claims in published maps and institutional affiliations.
Ready to submit your research? Choose BMC and benefit from:

- fast, convenient online submission

- thorough peer review by experienced researchers in your field

- rapid publication on acceptance

- support for research data, including large and complex data types

- gold Open Access which fosters wider collaboration and increased citations

- maximum visibility for your research: over $100 \mathrm{M}$ website views per year

At BMC, research is always in progress.

Learn more biomedcentral.com/submissions 